\title{
ASSESSMENT OF THE BALANCE OF GREENHOUSE GASES IN THE PRODUCTION OF RENEWABLE BIOMASS FROM SHORT-CYCLE ENERGY PLANTATIONS OF WILLOW
}

\author{
Aleh RODZKIN ${ }^{1}$, Sergey KOSTUKEVICH ${ }^{2}$, Wojciech TANAŚ ${ }^{3}$, \\ Mariusz SZYMANEK ${ }^{3}$, Flaieh Hammed KASSAR ${ }^{4}$ \\ ${ }^{1}$ Belarus National Technical University, BELARUS \\ ${ }^{2}$ Republican Institute of Professional Education, BELARUS \\ ${ }^{3}$ University of Life Sciences in Lublin, POLAND \\ ${ }^{4}$ University of AL- Muthanna, Rumaitha Samawa, IRAQ \\ E-mail of corresponding author: wojciech.tanas@ up.lublin.pl
}

Key words: greenhouse gas emissions, bioenergy, short rotation coppice, willow

\begin{abstract}
Greenhouse gas control it is the key aspect for climate protection. As climate regulation became inevitable, companies started adopting more proactive strategies. One of the effective methods for greenhouse gas emission calculation is based on life cycle analysis. A carbon footprint is defined as the sum of greenhouse gas emissions caused by an organization, event, or product and is expressed in terms of $\mathrm{CO}_{2}$ equivalents. The investigations were devoted to greenhouse emission assessment during life cycle of willow wood production from short rotation coppice plantations. In accordance with results about $48 \%$ of carbon dioxide gas from all life cycle of willow was emitted during wood harvesting and transportation to energy plants.
\end{abstract}

\section{INTRODUCTION}

The most important aspect of the Kyoto Protocol is the flexibility to achieve the set limits on greenhouse gas emissions. The basis of this system is the "bubble" principle, used in the US to control emissions of sulfur dioxide. In accordance with the Directive of the European Parliament and Council in the EU member states, from January 1, 2005, trade in greenhouse gas emission quotas began. According to the state's needs to reduce greenhouse gas emissions, the operator in a certain region is given the number of quotas that operators can throw into the atmosphere. If the operator emits less than the established quota, the difference between the established quota and the actual emission can be sold. Regression modeling of the dependence of greenhouse gas emissions on the consumption of primary fuel and energy resources and economic development of the sectors was used to forecast greenhouse gas emissions.

At present, more and more producers are joining the so-called "carbon clubs", whose goal is to reduce greenhouse gas emissions (Renato et al, 2015). This trend is due to number of reasons. Whereas in the early 1990s, corporations sought to block regulation of climate change-related issues, from the time they recognized such regulation in number of international instruments, they sought to develop an adaptive strategy. The companies saw new prospects for the market, improved reputation and production development in connection with climate regulation. In such circumstances, the most important issue is determining the amount of greenhouse gas emissions applied to the production of a particular type of product. Currently, one of the topical issues for businesses in the field of carbon strategy is the uncertainty of national policies in the field of greenhouse gas emissions regulation. One of the most effective methods is the calculation of the so-called "carbon footprint," based on the evaluation of the product life cycle. This approach is used by companies of various types of activities: industrial, energy, agricultural. Thus, studies were conducted to estimate greenhouse gas emissions in the production and use 
of electric vehicles. One of the sectors of agricultural production that accounts for a significant amount of greenhouse gas emissions is the production of beef (Subramaniam et al 2015). The purpose of the research performed in Brazil was to calculate the "carbon footprint" per kilogram of live weight. At the same time, various methods of obtaining products were taken into account (Ruviaro et al 2015). The need to estimate greenhouse gas emissions in the production of agricultural products and to develop new approaches aimed at reducing emissions is noted in a number of other publications (Hertwich et al, 2009; Tilman et al, 2011; Ruviaro et al, 2012). Gas emissions from renewable energy sources are not taken into account when calculating quotas. Nevertheless, it is necessary to take into account those greenhouse gases that are emitted during the life cycle of obtaining an energy resource. In this regard, the methods of "carbon footprint" have been actively disseminated in assessing the effectiveness of renewable energy sources. Large hydro power plants are the main source of electricity production on a renewable basis at present. The method for analyzing the life cycle and calculating the "carbon footprint" is the most effective for estimating the potential reduction of greenhouse gas emissions in the construction and operation of hydroelectric power stations (Zhang et al, 2015). Studies have shown that the low-carbon status of large hydropower plants is currently somewhat overvalued, and certain adjustments are needed to correct the situation in the future.

One of the most promising sources for obtaining thermal energy is biomass. To obtain biomass, it is also necessary to spend a certain amount of fossil fuel, which implies the emission of greenhouse gases. The Life Cycle Assessment (LCA) method was used in a number of studies related to various sources of biomass to generate energy, for example, algae (Lima et al, 2015).

These and other studies have shown that it is necessary to search for new approaches and technologies that allow reducing the amount of greenhouse gases in obtaining biomass (Dovi et al, 2009). One of the promising directions is the production of energy from the biomass of short-cycle tree plantations: willow, poplar, eucalyptus, etc. A study of the potential of fast-growing subspecies and hybrids of willow, poplar, aspen, miscanthus and other plants is being actively conducted in several countries (Sweden, Finland, Canada, Poland, and others) (Schweier et al, 2012). In this connection, a particular interest is caused by willow, as a plant capable of growing under conditions of high moisture content, on different types of soils characterized by different levels of fertility. The natural conditions of central and Eastern Europe make it possible to consider willow as a promising crop for the creation of commercial energy plantations. In accordance with the decisions of the Kyoto Protocol, greenhouse gas emissions from the burning of energy crops, as well as from other sources of biomass that are produced on a renewable basis and used for energy production, are not taken into account when establishing carbon credits. The purpose of our research was to estimate greenhouse gas emissions in the process of growing willow on energy plantations. The obtained results will allow to estimate the real decrease in the amount of greenhouse gases when using willow wood as biofuel in comparison with traditional energy carriers.

\section{METHODS OF RESEARCH}

Plantations of fast-growing willow were laid in the ecological conditions of the Republic of Belarus. According to the results of research carried out in different agroclimatic zones of country (Grodno, Mogilev, Minsk and Brest oblasts), the yield of willow in Belarus was 9-12 $t$ of dry wood per year, which corresponds to the indicators achieved in the USA or Sweden. 
The study of the morphological parameters of willow plants, to assess the dynamics of their growth and development in the field, was carried out according to the adopted methods (Dospechow 2012). The yield of willow was determined by weighing in continuous harvesting in the plots. The results of measurements of morphological parameters and yields of willows from each plot were processed by the method of variance analysis. The moisture content in willow wood and the specific heat of combustion were determined in laboratory conditions. Emissions of greenhouse gases were determined according to accepted international and national methods (Global Warming 1995).

\section{RESULTS AND DISCUSSION}

With a three-year cycle of wood production, the following results were obtained in experiments at the best sites: Developed peatlands: $9.9 \mathrm{t}$ of wood per hectare in terms of one year and 10 percent moisture; Loamy sod-podzolic soils: $12.5 \mathrm{t}$ of wood per hectare; Degraded peat-bog soils: $10.9 \mathrm{t}$ of wood per hectare in terms of one year and 10\% moisture.

Based on the results of the measurements the technology of cultivation of willow was adapted to specific soil and climatic conditions. The technology formed the basis for the development of technological maps for cultivation of crops, which in turn were used to perform economic calculations (Table 1).

Table 1. Technological map of obtaining willow wood. The area is 1 hectare

\begin{tabular}{|l|c|c|}
\hline \multicolumn{1}{|c|}{ Technological operation } & Fuel consumption, & \% of the total \\
\hline Soil cultivation & 57.4 & 12.67 \\
\hline Stubble abrasion (6-8) cm & 8.6 & 1.90 \\
\hline Preparation of the working solution of the herbicide & 0.9 & 0.20 \\
\hline Transportation of water in the field and filling of the sprayer & 1.8 & 0.4 \\
\hline Loading in a vehicle of mineral fertilizers & 0.2 & 0.04 \\
\hline Transportation and application of P and K fertilizers & 0.79 & 4.15 \\
\hline Plough land plowing & 18.8 & 4.15 \\
\hline Loading of mineral nitrogen fertilizers into the vehicle & 0.1 & 0.02 \\
\hline Loading of mineral nitrogen fertilizers into the vehicle & 5.3 & 1.17 \\
\hline Cultivation with harrowing & 3.6 & 0.79 \\
\hline Transportation and application of nitrogen fertilizers & 10.9 & 2.41 \\
\hline Landing & 13.4 & 2.96 \\
\hline Planting cuttings & 13.4 & 22.61 \\
\hline Care of plantings (7 cycles) & 96.6 & 21.32 \\
\hline Loading in a vehicle of mineral fertilizers & 1.4 & 0.31 \\
\hline Transportation and application of P and K fertilizers & 25.2 & 5.56 \\
\hline Loading of nitrogen fertilizers in the vehicle & 0.7 & 0.15 \\
\hline Transportation and application of nitrogen fertilizers & 25.2 & 5.56 \\
\hline Application of herbicides & 47.7 & 10.52 \\
\hline Plantation cleaning (7 cycles) & 217 & 47.88 \\
\hline Wood harvesting with loading and grinding & 133 & 29.35 \\
\hline Wood transportation & 84 & 18.53 \\
\hline The plowing of the plantation & 118.8 & 26.21 \\
\hline Plot of land & 18.8 & 4.15 \\
\hline Total & 453.2 & 100 \\
\hline
\end{tabular}

When growing willow, greenhouse gas emissions are associated with the use of diesel fuel for performing technological operations. 
When burning diesel fuel, the main greenhouse gas that is released into the atmosphere is carbon dioxide. The structure of fuel consumption and carbon dioxide emissions according to technological operations is shown in Figure 1.

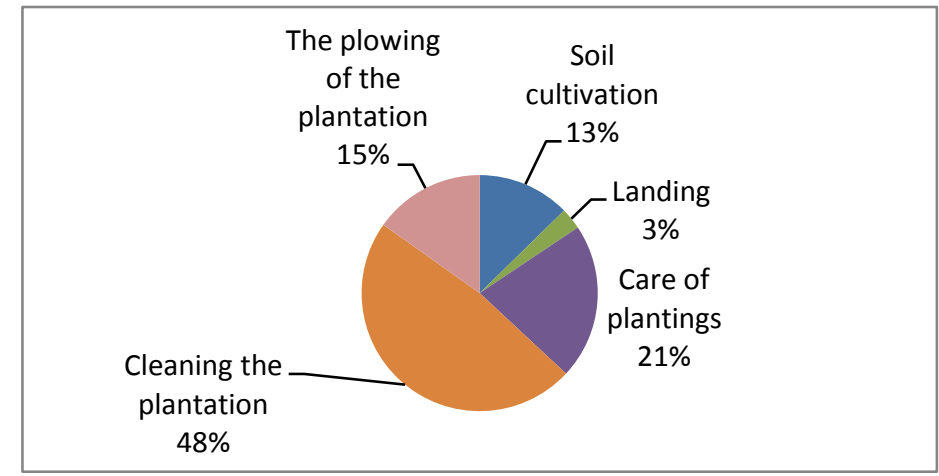

Figure 1. Structure of carbon dioxide emissions in the production of willow biomass according to technological operations

Cleaning is the most costly operation in terms of fuel consumption (Raucci et al 2015). Based on the results of the assessment conducted for 55 farms, over the course of 3 years, greenhouse gas emissions from technological operations were distributed as follows: harvesting and processing residues - 36\%, fertilizer application - 16\%, liming - 13\%, pesticide use $-7 \%$.

When growing willows, more significant cleaning costs are associated with a relatively high crop yield. A significant impact on greenhouse gas emissions of technological operations related to the harvesting of short-cycle crops has been noted in other publications (Berhongaray and Ceulemans, 2015). At the same time, it is stressed that special attention should be given to such a technological operation as weed control. In particular, it is from this aspect that the carbon balance in the soil largely depends. In our studies, an estimate of the emissions associated with soil carbon during the cultivation of willow on short-cycle plantations was not carried out.

The average calorific value of willow wood installed in our experiments was $18500 \mathrm{~J} / \mathrm{kg}$. This means that in terms of a year from one hectare of plantation, you can get $4.4 \mathrm{t}$ of equivalent fuel, which is equivalent to about 3.9 thousand $\mathrm{m}^{3}$ of natural gas and $3.2 \mathrm{t}$ of heating oil.

In accordance with the obligations of the Republic of Belarus on the UN Framework Convention on Climate Change and the current market in the EU ETS system, the cost of one ton of carbon dioxide can be about 15 euros (Subramaniam et al, 2015).

Thus, replacing fossil fuel with willow wood as an energy carrier will potentially allow about 4,000 euros per hectare of willow plantation over the entire life of the will, if the mechanism for trading carbon credits at the local level is implemented. Of course, this approach will serve as an additional incentive for wood producers for energy purposes from short-cycle plantations.

\section{CONCLUSION}

The receipt of any kind of renewable energy is associated with the use of fossil fuels (diesel, gasoline, natural gas, etc.). One of the most effective methods for estimating greenhouse gas emissions in the production process is the LCA method. The research proves the effectiveness of such an approach for estimating greenhouse gas emissions in obtaining wood for energy purposes from short-cycle willow plantations. The main 
amount of emissions is associated with the use of diesel fuel in the cultivation of plantations. Calculations carried out taking into account the optimal planned plant life (22 years from the moment of planting) showed that the main carbon dioxide emissions (48\%) are related to such a technological operation as harvesting and transportation of wood. Reduce emissions is possible when optimizing the logistics of these technological operations. In particular, the organization of movement of harvesting equipment, optimization of cleaning, loading and transportation schemes, etc. Of great importance is the distance from the plantation of willow to the consumer (thermal power plant). From one hectare of willow, taking into account its yield and specific heat of combustion, it is possible to obtain 4.4 tons of equivalent fuel, which is equivalent to about 3.9 thousand $\mathrm{m} 3$ of natural gas and 3.2 tons of heating oil. The amount of $\mathrm{CO}_{2}$ emissions from burning willow wood for energy purposes will be 12,467 tons. For the entire service life (in terms of plantation area of 30 hectares), emissions associated with the consumption of diesel fuel will total $734 \mathrm{t}$. When replacing natural gas with an equivalent output energy, the amount of wood willow is a positive $\mathrm{CO}_{2}$ balance of 11,733 t. The cost of a quota for emissions of one tonne-equivalent of $\mathrm{CO}_{2}$ is currently on the international market of about 15 euros. Replacement of fossil fuels with willow wood is thus both environmentally and economically justified, both at the country level and individual energy producers. The implementation of this approach at the local level will serve as an additional incentive for wood producers for energy purposes from short-cycle plantations.

\section{REFERENCES}

Berhongaray, G. \& Ceulemans, R. (2015). Neglected carbon pools and fluxes in the soil balance of shortrotation woody biomass crops. Biomass and Bioenergy, 73, 62-66.

Dospiechow, B.A. (1985). Technique of field experience. Kolos, p. 416.

Dovì, V.G., Friedler, F., Huisingh, D., \& Klemes, J.J. (2009). Cleaner energy for a sustainable future. Journal of Cleaner Production, 17 (10), 889-895.

Global Warming Potentials. Climate Change 1995, The Science of Climate Change: Summary for Policymakers and Technical Summary of the Working Group I

report//http://unfccc.int/ghg_data/items/3825.php http://dx.doi.org/10.1016/j. jclepro. 2009.02.001.

Hertwich, E.G., \& Peters, G.P. (2009). Carbon footprint of Nations: a global, Trade-Linked analysis. Environmental Science Technolgy, 43, 64140-6420.

Jin Zhang, \& Xu Linyu (2015). Embodied carbon budget accounting system for calculating carbon footprint of large hydropower project. Journal of Cleaner Production, 96, 444-451.

Lima, D.M., Sales, A.E., \& Kiperstok, A. (2015). Energy production from microalgae biomass: carbon footprint and energy balance. Journal of Cleaner Production, 96, 493-500.

Orsato, R. J., Guilherme F. de Campos, Barakat, R. S., Nicolletti, M. \& Monzoni, M. (2015). Why join a carbon club? A study of the banks participating in the Brazilian Business for Climate Platform. Journal of Cleaner Production, 96, 387-396.

Ruviaro, C.F, Cristiane Maria de Léis, Vinicius de N. Lampert, Barcellos, J.O., \& Dewes H. (2015). Carbon footprint in different beef production systems on a southern Brazilian farm: a case study. Journal of Cleaner Production, 96, 435-443.

Ruviaro, C.F., Gianezini, M., Brandao, F.S., Winck, C.A., \& Dewes, H. (2012). Life cycle assessment in Brazilian agriculture facing worldwide trends. Journal of Cleaner Production, 28, 9-24.

Schweier, J., \& Becker, G. (2012). Harvesting of short rotation coppice-harvesting trials with a cut and storage system in Germany. Silva Fennica, 46 (2), 287-299. 
Subramaniam, N., Wahyuni, D., Cooper, B.J., Leung, P., \& Wines, G. (2015). Integration of carbon risks and opportunities in enterprise risk management systems: Evidence from Australian firms. Journal of Cleaner Production, 96, 407-417.

Tilman, D., Balzer, C., Hill, J., \& Befort, B.L (2011). Global food demand and the sustainable intensification of agriculture. Proceedings of the National Academy of Sciences USA, 108, 20260-20264. 